\title{
Pharmaceutical Applications of Chitosan Extracted from Local Marine Sources
}

\author{
MANUELA R. APETROAEI ${ }^{1}$, ILEANA RAU2*, CARLA CEZARINA PADURETU², GABRIELA LILIOS ${ }^{3}$, VERGINICA SCHRODER ${ }^{3}$ \\ 1Mircea cel Batran Naval Academy, Faculty of Navigation and Naval Management, 1 Fulgerului Str., 900218, Constanta, Romania \\ 2University Politehnica of Bucharest, Faculty of Applied Chemistry and Materials Science, 1 Polizu Str., 011061, Bucharest, \\ Romania \\ ${ }^{3}$ Ovidius University of Constanta, Faculty of Pharmacy, 1 Universitatii Alley, Campus Corp B, 900470, Constanta, Romania
}

\begin{abstract}
Identification of chitosan from new local marine sources could be a greatchallenge for research in terms of using this biopolymer in various pharmaceutical, environmental or food applications. In the present study, two chitosan powder samples extracted from processed shrimps waste and Rapana venosa eggs capsules were compared with a food supplement sample based on chitosan, from the point of view of spectral analyses (FTIR spectroscopy), of their solubility in dilute acetic acid solutions (1\%), insoluble substances content, and fats binding capacity. In order to determine the fat binding capacity of the tested chitosan samples, different types of cold pressed vegetables oils (olive oil, sunflower oil, soybean oil, argan oil and coconut oil) and animal fats (butter and pork lard) were used. The present study highlighted that the chitosan samples, chemically extracted with low financial efforts by waste recovery of crustaceans and mollusks from Romanian Black Sea coast, could be an important source with high potential. The obtained results showed a good fat binding capacity, especially for chitosan samples extracted from shrimps waste compared to the chitosan sample chosen as reference. These compounds may be successfully used in pharmaceutical applications, in various formulations as dietary supplement, or as useful therapeutic component in the hypocholesterolemia treatment or in prevention of cardiovascular risk, due to their good solubility in dilute acidic solutions and lower values of insoluble content.
\end{abstract}

Keywords: chitosan, food supplement, solubility, fat binding capacity

Known as the most abundant polymer in the world after cellulose, chitosan is extracted from various marine sources: crustaceans exoskeleoton, insects, fungi [1 - 3] or eggs capsules of marine snail [4]. Due to its biocompatibility, biodegradability and muchoadhesivity, the chitosan could become an interesting candidate in different biomedical and pharmaceutical applications as: wound dressings [5], blood anticoagulant [6], drug delivery systems [7], hemostatic agent [6].

According to literature data, pharmaceutical use of chitosan in obesity and hypocholesterolemia treatments is due to its ability to react with bile acids in the digestive tract in order to increase their excretion [8].

Its good solubility in diluted inorganic and organic acids or the good binding capacity of fats is due to the presence of free hydroxyl and amino groups in glucopyranose structure which explains the cationic behaviour of chitosan. These properties of chitosan are influenced by its molar mass, deacetylation degree and the origin of the extracted sources.

This is why there are many pharmaceutical products based on chitosan such as hemostatic dressings specific for wound healing, nutraceutical products or food supplements [3].

The aim of the present study is to investigate and to compare two chitosan samples extracted from local marine sources with a commercial food supplement based on chitosan from Romanian market, in order to use them as nutraceuticals or food supplements, according to United States Pharmacopeia 34-NF 29 and ASTM F 2103-11.

\section{Experimental part}

Materials and methods

The new chitosan samples were extracted from two different local marine sources: waste of Palaemon elegans (shrimps) -the extracted chitosan (Pe-Ch) having a molar mass of $M=150-200 \mathrm{kDa}$ (determined by viscometry, at $t=25^{\circ} \mathrm{C}$ ) and Rapana venosa eggs capsules - the extracted chitosan (Rec-Ch) having a lower molar mass of $M_{\mu}=1.5-$ $3 \mathrm{kDa}$. A food supplement based on chitosan (FS-Ch) purchased from Romanian market was used as reference for comparative purpose. According to manufacturer information, the chitosan reference sample (FS-Ch) was obtained by extraction from marine crustaceans exoskeleton. The molar mass of this chitosan was $M_{\mu}=200$ $-270 \mathrm{kDa}$. According to the supplement recommendations the FS - Ch sample exhibits an enhanced efficiency in prevention and overweight treatement due to the chitosan ability to bind the fat compounds and therefore their absorption during the digestion is reduced and the normal blood serum cholesterol level is maintained.

All the chitosan samples were evaluated from the point of view of spectral characterization (FTIR analyses), solubility in acetic acid solutions (1\%), fat binding capacity and insoluble impurities according to United States Pharmacopeia 34-NF 29 and ASTM F 2103-11.

Spectral characterisation was performed for solid samples using an Interspec 200-X FTIR equipment in transmittance with a frequency range between 4000 and $400 \mathrm{~cm}^{-1}$, at a resolution of $4 \mathrm{~cm}^{-1}$ to identify the main chemical characteristics groups of the studied samples of Pe-Ch, Rec-Ch and FS-Ch.

The solubility of chitosan samples was tested in dilute solutions of $1 \%$ acetic acid, at $t=25^{\circ} \mathrm{C}$, in triplicate, by applying a modified and improved method of FernandezKim [9].

Each analyzed chitosan sample $(0.1 \mathrm{~g})$ was added into a centrifuge tube of known weight. A volume of $10 \mathrm{~mL}$ acetic acid solution $1 \%$ was mixed in each tube with chitosan sample. All tested samples were shaken in a 
vortex mixer for $15 \mathrm{~min}$ at $800 \mathrm{rpm}$ and then were dipped in a heated bath $\left(60^{\circ} \mathrm{C}\right)$ for $10 \mathrm{~min}$. The samples cooled at room temperature were centrifuged for 10 minutes, at $10,000 \mathrm{rpm}$. The removal of the acidic supernatant was carried out by successive washing (three times) of the obtained precipitate with the distilled water, by centrifuging. Finally, the undissolved particles were dried at $60{ }^{\circ} \mathrm{C}$ for $24 \mathrm{~h}$ and solubility of chitosan samples was calculated according to $[9,12]$. As equipment, a VELP Digital IR Vortex mixer and a centrifuge were used.

The fat binding capacity (FBC) was determined for cold pressed vegetable oils (olive oil, sunflower oil, soybean oil, argan oil and coconut oil) as well as for fats of animal origin (butter and pork lard). A modified and improved method of Knorr [10] and Rout [11] was employed.

The centrifuge tubes were weighed, and an amount of 0.25 g of each chitosan sample was added in each tube. A volume of $5 \mathrm{~mL}$ of the tested sample oil was added. In order to disperse the chitosan particles in the oil mass, all tubes were shaken in a vortex mixer for 1 minute at $800 \mathrm{rpm}$. Then, the prepared samples were left at room temperature for 30 minutes with intermittent shaken in vortex mixer for 1 minute at $800 \mathrm{rpm}$, every 10 minutes. After this time, the samples were centrifuged for 25 minutes at $4000 \mathrm{rpm}$. The oily supernatants were removed and the tubes with finally chitosan samples were weighed. All measurements were realized in triplicate, at room temperature.

Fat binding capacity (FBC) of the tested chitosan samples was calculated according to [9].

The insoluble content (IS) provides information about stability of chitosan in diluted acid solutions. The method of insoluble content determination is based on dissolving the chitosan powder samples $(0.1 \mathrm{~g})$ in acetic acid solutions (1\%), and filtering the chitosan acidic solutions. Finally, this parameter (IS) is calculated from the weight of chitosan dissolved and the weight of insoluble particles obtained on a filter paper. All measurements were carried out at $t=25( \pm 1){ }^{\circ} \mathrm{C}$ in triplicate.

The percentage of insoluble content characterized the total amount of insoluble impurities from chitosan pow der samples [12].

\section{Results and discussions}

The new chitosan powder samples (Pe-Ch, Rec-Ch) extracted from local marine sources were characterized by FTIR spectroscopy and the recorded spectra were compared with that of the sample of food supplement based on chitosan (fig. 1).

From the IR spectra of tested chitosan samples (fig.1), the similarities of characteristics chitosan groups of all three tested samples for transmittance band could be observed. The peaks registered at $1709 \mathrm{~cm}^{-1}, 1702 \mathrm{~cm}^{-1}$ and $1690 \mathrm{~cm}^{-1}$ in the FS-Ch, Pe-Ch and Rec-Ch spectra are assigned to stretching vibrations of $\mathrm{C}=\mathrm{O}$ from $\mathrm{NH}-\mathrm{CO}-\mathrm{CH}_{3}$ (Amide I band).

The vibrations registered at $1638 \mathrm{~cm}^{-1}, 1633 \mathrm{~cm}^{-1}$ and $1606 \mathrm{~cm}^{-1}$ are assigned to $\mathrm{NH}_{2}$ - bending (amino groups) specific to chitosan structure from the three samples [13, 14]. It can be observed that the specific peaks of chitosan are found at the specified wavenumbers for all the three analyzed samples, which confirms its structure.

Solubility of analyzed chitosan samples in weak acid solutions $(\mathrm{pH}=4-6)$ is due to the presence of the amino groups in the polymer chain structure, which confered it a cationic character [15]. The results obtained are presented in table 1.

As observed in the table 1, the tested Pe-Ch samples revealed a comparable solubility to that of FS-Ch sample. These results indicate that a high purity chitosan is obtained.

The solubility values for the chitosan powder Rec-Ch samples indicates the presence of some organic impurities (proteins), which have notbeen completely removed during the deproteinization step.

Table 1

SOLUBILITY RESULTS OF TESTED CHITOSAN SAMPLES

\begin{tabular}{|l|l|}
\hline Chitosan sample type & $\mathrm{S}(\%)^{*}$ \\
\hline FS-Ch & $98.00 \pm 2.83$ \\
\hline Pe-Ch & $90.95 \pm 1.49$ \\
\hline Rec-Ch & $72.65 \pm 2.90$ \\
\hline
\end{tabular}

Nevertheless the good solubility of the tested chitosan powders in acetic acid diluted solutions (1\%) recommends them to be used in pharmaceutical aplication [16], as a drug - carrier [17], or injectable solutions formulation [18], or in environmental applications as saline solutions [19]. Nessa et al. [20] obtained chitosan with solubility ranging between 44.3 and $97.2 \%$ and these results were correlated with the purity of the tested samples.

Fat binding capacity (FBC) measures the ability of chitosan to bind or adsorb fats, being a main characteristic in choosing this biopolymer as a food supplement. Five types of cold pressed vegetable oils (olive oil, sunflower oil, soybean oil, argan oil and coconut oil) and two types of animal fats (butter and pork lard) were used for FBC determination of tested chitosan samples. Both vegetable oils and animal fats are characterized by a different content of saturated fatty acids (bad fats) as well as monounsaturated and polyunsaturated fatty acids (good fats). Bad fats are responsible for high blood pressure, heart attack, atherosclerosis and increased blood cholesterol. Therefore, it is necessary to find compounds that adsorb

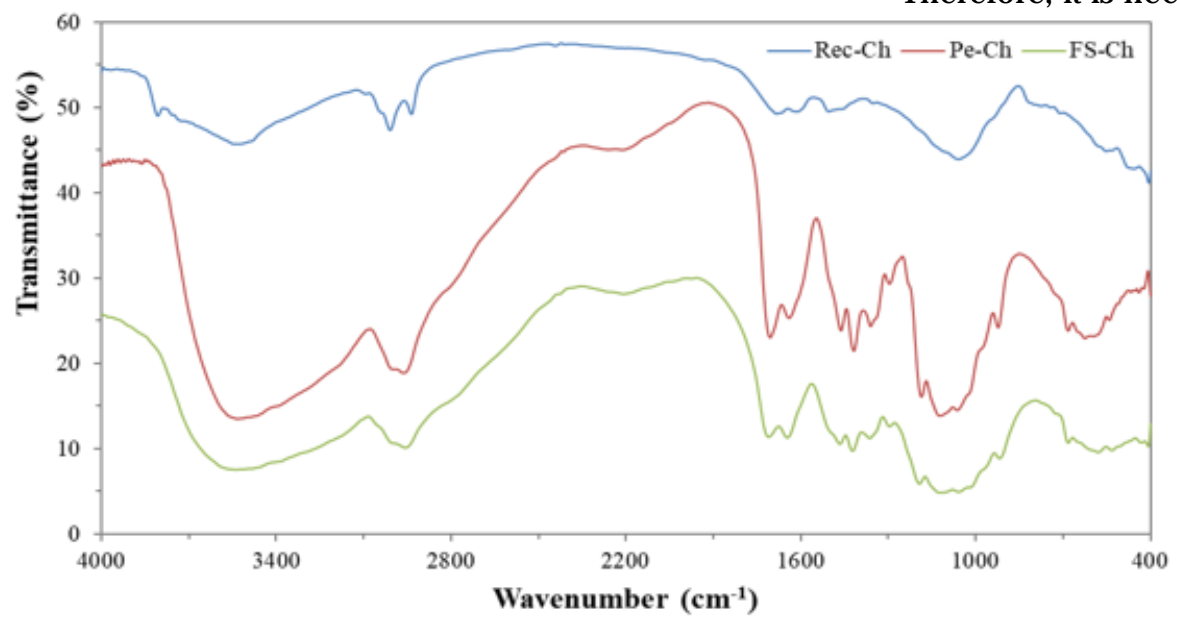

Fig. 1. FTIR spectra of tested chitosan samples 
Table 2

FAT BINDING CAPACITY RESULTS OF TESTED CHITOSAN SAMPLES AND FATS CHEMICAL COMPOSITION [21, 22]

\begin{tabular}{|c|c|c|c|c|c|c|}
\hline \multirow[b]{2}{*}{ Oil Type } & \multicolumn{3}{|c|}{ Fat composition } & \multicolumn{3}{|c|}{ Chitosan Types } \\
\hline & $\begin{array}{l}\text { Monounsaturated } \\
\text { fatty acids (\%) }\end{array}$ & $\begin{array}{l}\text { Polyunsatured } \\
\text { fatty acids (\%) }\end{array}$ & $\begin{array}{l}\text { Saturated } \\
\text { fatty acids } \\
(\%)\end{array}$ & FS-Ch $(\%)^{*}$ & $\mathrm{Pe}-\mathrm{Ch}(\%)^{*}$ & Rec-Ch $(\%)^{*}$ \\
\hline Sunflower oil & 26 & 63 & 10 & $262.3 \pm 10.7$ & $854.8 \pm 32.6$ & $328.0 \pm 15.8$ \\
\hline Olive oil & 73 & 11 & 14 & $218.4 \pm 12.0$ & $860.1 \pm 32.6$ & $339.0 \pm 16.2$ \\
\hline Soybean oil & 66 & 26 & 8 & $229.7 \pm 23.8$ & $831.6 \pm 24.5$ & $309.0 \pm 10.5$ \\
\hline Argan oil & $43-49$ & $29-36$ & $19-20$ & $211.4 \pm 11.8$ & $725.7=15.0$ & $256.0=7.4$ \\
\hline Coconut oil & 6 & 2 & 86 & $197.5 \pm 10.4$ & $741.0=20.7$ & $284.0=9.8$ \\
\hline Butter & 70 & 25 & 3 & $293.0 \pm 13.5$ & $789.1=22.4$ & $311.0=11.5$ \\
\hline Pork lard & 45 & 11 & 39 & $209.5 \pm 10.6$ & $769.2 \pm 21.3$ & $304.5=10.5$ \\
\hline
\end{tabular}

and remove saturated fatty acids in the body and maintain the balance of monounsaturated and polyunsaturated acids.

For FBC determination of all the three chitosan samples, the procedure described in the previous section was used and the results are presented in table 2 .

As shown in table 2, the highest values of the FBC for all fat types, compared to the other two tested chitosan samples were obtained for Pe-Ch samples. For this chitosan (Pe-Ch) comparable FBC values were recorded for vegetable fats from soybean oil, sunflower and olive oil and proximate $\mathrm{FBC}$ values were obtained for butter and pork lard. In the case of Rec-Ch chitosan the obtained FBC values are higher than those obtained for the food supliment (FS-Ch) for all the fats tested. It can be concluded that the new chitosan samples presented affinity both for monounsaturated fatty acids and saturated fatty acids.

This mechanism is possible because chitosan is considered a weak base with positively amino charged which attract negative anions of fatty acids and is responsabile for the cholesterol lowering effect $[23,24]$.

Due to this good adsorption capacity, especially of circulating cholesterol, it is necessary to continue the study of new chitosan samples to be used as useful nutraceutical compounds in the hypocholesterolemia therapy for prevention of cardiovascular risk. Bokura etal. [26] affirm that chitosan is safe and effective for cholesterol lowering, thus a significant decrease of total serum cholesterol was observed after 8 weeks at the subjected elderly women.

In our study, the obtained results showed that the two new-chitosan types extracted from various marine sources with different molar mass values have a good fat binding capacity and could be used in the food industry or pharmaceutical applications.

Similar results were obtained for FBC by No et al. [27] who obtained for a commercial chitosan values ranging between 217 and $403 \%$ for soybean oil and by Nessa etal. [20] who showed that samples of chitosan extracted from local sources (shrimps) had for soybean oil FBC values ranging between 346 and $748 \%$.

Insoluble content (IS) is a measure of chitosan purity degree, being influenced by its extraction procedure. Chitosan obtained by chemical extraction may contain impurities as heavy metals or proteins and their values are limited when the application area of the biopolymer is pharmaceuticals or food [12, $28-30]$. These impurities could cause difficulties in chitosan leaching or prevent its formulation based drug delivery system for biomedical applications.

The new chitosan samples were compared in terms of insoluble content with that of FS-Ch. The obtained results are presented in figure 2.

As it can be seen from figure 2, IS content values of the tested samples are situated within the limits stipulated in

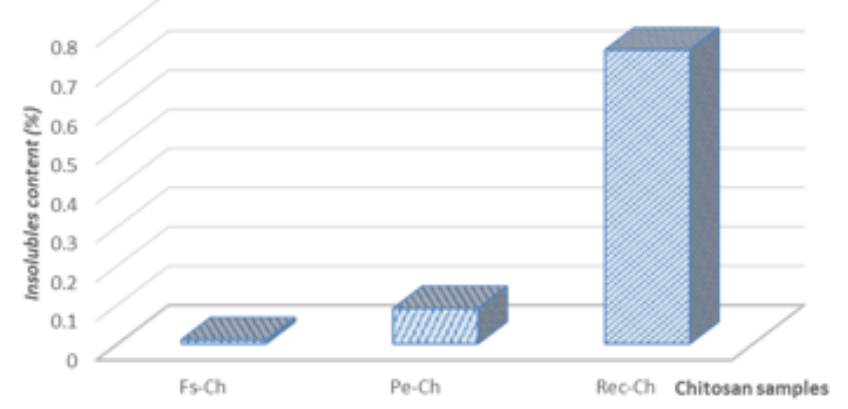

Fig. 2. Insoluble content of tested chitosan samples

USP 34-NF 29, which recommends an IS content of less than $1 \%$ for chitosan used in biomedical applications. Compared to the FS-Ch sample, chosen as a reference with an IS content of $0.01 \%$, the Pe-Ch sample has a comparable value, $I S=0.09 \%$. The $I S$ value of $0.75 \%$ for Rec-Ch sample is due to the presence of organic impurities (proteins and indoles) in the chitosan powder and it is correlated with the results obtained in the solubility test. This feature of chitosan completed its characterization in terms of solubility and stability, in order to find the appropriate applications area [16, 31 - 33].

\section{Conclusions}

In this paper the two chitosan samples (Pe-Ch and Rec$\mathrm{Ch}$ ) extracted from local marine sources were compared with a food supplement sample based on chitosan, chosen as reference. The obtained results showed that from the spectral point of view, all three chitosan samples are similar and the IR spectra presented peaks of characteristic groups from chitosan structure in the transmittance bands. Also, the study showed a good solubility of new chitosan samples in acetic acid solutions of $1 \%$ and low content of insoluble impurities. These characteristics suggest the new chitosan powders could be used as drug carriers, either in oral or injectable solutions formulations.

Although the marine sources are different: shrimps waste ( $P$. elegans) and $R$. venosa eggs capsules, new chitosan samples showed a good fat binding capacity, which recommend it as useful curative compound in the hypocholesterolemia therapy with atherogenic effects, in prevention of cardiovascular risk or hepatic steatosis.

\section{References}

1. DASH, M., CHIELLINI, F., OTTENBRITE, R.M., CHIELLINI, E., Prog. Polym. Sci., 36, 2011, p. 981.

2. IFUKU, S., Molecules, 19, 2014, p.18367.

3. SZYMANSKA, E., WINNICKA, K., Mar. Drugs, 13, 2015, p. 1819. doi:10.3390/md13041819

4.APETROAEI, M.R., ZGARIAN, R.G., MANEA, A.M., RAU, I., TIHAN, G.T., SCHRODER V., Mol. Crys. Liq. Crys., 628, 2016, p.102. 10.1080/ 15421406.2015.1137681 
5. HURLER, J.,SKALKO-BASNET, N., J. Funct. Biomat, 3, 2012, p. 37. 6. OKAMOTO, Y., YANO, R., MIYATAKE, K.; TOMOHIRO, I., SHIGEMASA, Y., MINAMI, S.,Carbohydr. Polym.,53, 2003, p. 337.

7. SZYMANSKA, E., WINNICKA, K.,Acta Pol. Pharm. Drug Res.,69, 2012, p. 509.

8. BAKER, W.L., TERCIUS, A., ANGLADE, M., WHITE, C.M., COLEMAN, C.I., Ann. Nutr. Meta.,55, 2009, p.368.

9.FERNANDEZ-KIM, S.O., Dissertation thesis, Louisiana St. University, Baton Rouge, LA, USA, 2004.

10.KNORR,D., J ournal of Food Science,47, 1982,p. 593.

https://doi.org/10.1111/j.1365-2621.1982.tb10131.x

11. ROUT,S.K., Dissertation thesis. Louisiana St. University, Baton Rouge, LA, USA, 2001.

12.*** ASTM F 2103, Standard Guide for Characterization and Testing of Chitosan Salts as Starting Materials Intended for Use in Biomedical and Tissue Engineered Medical Product Applications; 2011. https:// doi.org/10.1520/F2103-11

13.KAYA,M., BARAN,T., MENTES,A., ASAROGLU,M., SEZEN,G., TOZAK,K.O., Food Biophysics,9, 2014,p. 145. doi: 10.1007/s11483-0139327-y

14.SIMONESCU, C.M., MARIN, I., TARDEI, C., MARINESCU, V., OPREA, O., CAPATINA, C., Rev. Chim. (Bucharest) 65, no 6, 2014, p. 627. 15.RINAUDO,M., Progress in Polym. Sci.,31, 2006, p. 603. 16.WALKE, S., SRIVASTAVA, G., NIKALJE, M., DOSHI, J., KUMAR, R. RAVETKAR, S., Doshi, P., Int. J. Pharm. Sci. Rev. Res., 26, no2, 2014, p. 215.

17.CASTRO, S.P.M., PAULIN, E.G.L., InTECh, 2012, pp. 1. http:// dx.doi.org/10.5772/51200 (accessed inAugust, 2017).

18.LI, Y., ZHANG, Y., WEI, Y., TAO, L., J Vis Exp., 127, 2017. doi: $10.3791 / 56253$

19.APETROAEI, M.R., PADURETU, C., RAU, I., SCHRODER, V., Chem. Papers, 72,no8, 2018, p. 1853.DOI: 10.1007/s11696-018-0440-8.
20.NESSA,F., MASUM,S., ASADUZZAMAN,M., ROY,S.K., HOSSAIN, M.M., JAHAN,M.S.,Bangladesh J. Sci. Ind. Res.45, no 4, 2010, p. 323.

21.DOSTALOVA,J., IK,P.H., REBLOVA,Z., POKORNY, ., Czech J. Food Sci., 23, no 6, 2005, p. 230. DOI: 10.17221/3396-CJFS.

22.*** https://theconsciouslife.com/foods/lard-04002.htm (accessed in July 2018).

23. GLICKMANN, R.M., eds. Green, M. and Green, H.L., Ac. Press, Inc., Orlando, 1984, p 145.

24. RODRIGUEZ, M.S., ALBERTENGO, L.E., Biosci. Biotechnolog. Biochem. 69, no 11, 2005, p. 2057.

25. GEGIU, G., BRANZA A.D., BUCUR, L., GRIGORIAN, M., TACHE, T., BADEA, V., Farmacia, 63, no. 2, 2015, p. 275.

26.BOKURA, H., KOBAYASHI, S., Eur. J. Clin Nutr., 57, 2003, p. 721. 27.NO, H.K., LEE, K.S., MEYERS, S.P, J. of Food Sci.65, no.7, 2000b, p.1134.

28. *** THE UNITED STATES PHARMACOPEIA; USP 34-NF 29; The United States Pharmacopeial Convention: Rockville, MD, USA, Second Suppl., 2011, p. 5361.

29. KAMARI, F.H., NECHIFOR, A.C., MUHAMMED, A.A., ALBU, P.C., CRACIUN, M.E., Rev. Chim. (Bucharest), 66, no. 5, 2015, p. 615.

30. BUCUR, L., TARALUNGA, G., SCHRODER,V.,Farmacia, 64, no.2, 2016, p. 198.

31. ZHANG, J., XIA, W., LIU, P., CHENG, Q., TAHIROU, T., GU, W., LI, B., Mar. Drugs,8, 2010, p. 1962.doi:10.3390/md8071962.

32. SIMONESCU, C.M., TATARUS, A., TARDEI, C., PATROI, D., DRAGNE, M., CULITA, D.C., PATESCU, R.E., BUSUIOC, LT., MELINTE, I., Rev. Chim. (Bucharest), 66, no. 5, 2015, p. 732.

33. MOUSA, N.E., SIMONESCU C.M., PATESCU R.E., LAVRIC, V., CULITA, D.C., Rev. Chim.(Bucharest), 68, no. 9, 2017, p.1992.

Manuscript received: 9.11 .2018 